\title{
Teaching of Philosophy as a System Core of Modern Higher Education
}

\author{
Irina Ponizovkina \\ Department of Philosophy \\ Plekhanov Russian University of Economics \\ Moscow, Russia \\ Email: irina-ponizovkin@mail.ru
}

\begin{abstract}
The article is dedicated to the urgent issues and the role of lecturing philosophy in the higher schools. The author believes, the philosophical and humanitarian education shall become a strategic core of educational processes in the higher schools and make them more effective. The article also draws attention to the significance of the philosophical education to a society.
\end{abstract}

Keywords - contemporary higher education; philosophical education; philosophy; education

\section{INTRODUCTION}

The reform of the Russian professional education on the Western model was designed to improve the quality of education and the competence of the experts, that were on a noticeable decrease during the Perestroika. In fact, the educational amateurism of one kind was replaced or rather supplemented by the amateurism of another kind, which may turn out to be even more dangerous for a society. Amateurism is usually understood as the superficiality of knowledge and of judgment: "a little bit of everything". But almost no one, except for philosophers, is talking about the amateurism of a different kind, widely spread over the past decade, thanks to a new model of the higher education: an indepth study of specific professional fields in their isolation from the context and the totality of real life facts, broader humanitarian issues.

There is another recipe to overcome both types of modern educational amateurism - to return to universities the complete philosophical and humanitarian education, which is now perceived by the education officials rather as an unnecessary appendage, just increasing the cost of educational programs. This can be seen as not only as narrow-mindedness but also as short-sightedness of those responsible for the strategy of the current educational strategy of Russia.

However, contrary to today's distinctly positivistpragmatic setting for downplaying the role of philosophical knowledge and even getting rid of philosophy in the educational process, a centuries-old spiritual and social practice show us, that philosophy is alive and well, and will live also in education. Moreover, philosophy aims at helping to solve many problems accumulated in the sphere of education and society in general.

\section{THE SignifiCANCE OF PHILOSOPHICAL EDUCATION TO SOCIETY}

The social upheavals of the 21st century, aggravation, and deepening of the ecological problems, local conflicts, socio-political contradictions revealed their dependence on the nature of society management and the importance of spiritual and moral components. Yet, many subjects of market relations, professional graduates, are not inscribed into a specific cultural and historical context of the time, its spiritual and social issues, human values, and are unable to look broadly at the interconnected problems of a society (including their own professional problems), to comprehend them through the socio-ethical categories and concepts of social responsibility.

This can have disastrous consequences to a globalizing unstable world. In the modern age of the complex and uncertain dynamic systems, the moral responsibility of the actors-experts for their actions and their socio-historical implications rises manifold. The entrepreneurs, teachers, engineers etc. are required not to think in "causal chains", but in "causal networks", to predict the social processes, take into account diverse interests and interdependence of social and natural environment, provide a social and axiological assessment of emerging situations.

The restricted professional disciplines do not teach all these. The economists (professors and invited businessmen) somehow manage to lecture the course "Corporate Social Responsibility" never uttering the word "morality" and often focus on the financial gain of the corporate social responsibility. Under these circumstances, the following fact is alarming if not surprising. There was no single future economist, a student of the several academic groups, who had answered "Moral values" or "Conscience" to the question "What guides your activities?". The most popular answers were "profit", "success", "result", "interests", "needs". The youth is pragmatically focused nowadays. The current situation of the total commercialization of all the spheres of society has caused a serious imbalance in the system of axiological attitudes, overshadowing the setting of values and ideals, guiding and inspiring people. This 
threatens with the ethical blindness in their professional activities, which danger is being actively discussed in the West ${ }^{1}$.

The Western society has already embarked on the path of awareness of these problems, and philosophical degree only adds to the authority of an individual in any discipline and profession. The companies often invite such "non-major" experts-philosophers to the top positions or as consultants. There is, however, a frequent appeal in Russia to the experience of the Western countries in the field of the higher education, when trying to prove that philosophy is not given so much attention and contact hours. Yet it is often forgotten that there is a clearly defined multi-tier system of philosophical education in the West. There is a special program "Philosophy for children", supported by UNESCO and distributed in 50 countries including the USA, Germany, the UK, France, Brazil, Australia, etc. In the USA, e.g., the children start to learn philosophy in kindergartens, following the specially described techniques (M. Lipman, A. Sharp, et al), then the inclusion in philosophy becomes deeper in school and college. So a young person comes to a university with a good philosophical background.

This is supported by my own experience of lecturing to the Western students who initially had a fairly profound knowledge of the philosophical disciplines acquired in schools and colleges. According to statistics, the number of people in the US, majoring in philosophy, is growing steadily. Philosophy is in the top-20 of the American ranking of the most prestigious professions, consisting of several hundred positions. There is also Institute of Philosophical Practice in France, in which the philosophers provide assistance to the population concerning the spiritual and moral issues. The Institute's popularity surpasses the existing institutions of psychological support.

There is a stable worldwide trend of humanization and socialization of business and economic relations. At the time, the Volkswagen Group Vice-President K. Schneider made an eloquent confession that during the harsh times the Group's address to the leading economists didn't yield the desired results. "It was apparent, that the rapidly changing conditions of the contemporary market require a more global, unorthodox thinking. Then we appealed to the philosophers and, as it was later confirmed, we were not mistaken" [http://www.club-management.org/content/view/250/27/]. This shall not be a surprise that Volkswagen Group was the founder of the private university "Auto-Uni", in which most of the major fields of study and research projects for the future engineers, marketing specialists and senior executives include a fair number of topics, intellectual skills and courses belonging to the humanities and social sciences. Volkswagen was able to see the future of the humanities and social sciences: it is very useful to discuss complex philosophical problems for any successful professional activity [1].

\footnotetext{
${ }^{1}$ The concept of "ethical blindness" has become widely used in the Western business practices and management theory in 2008 during the financial and then economic crisis, when this phenomenon was manifested most vividly.
}

\section{THE SIGNIFICANCE OF PHILOSOPHY FOR MODERN EDUCATION}

In the modern era of informatization and postmodernity, in the reign of eclecticism, relativism and pragmatism relating to values (including the educational ones) [2], the mindset on consumerism is not surprising, as not surprising is the educational-methodological fascination with restricted, applied, instrumental specializations and courses to the detriment of profound basic education. This corresponds at large with the ruling clipped, mosaic thinking, the domination of which is fully manifested in the educational environment. The developed multimedia technologies (TV, Internet, advertising, etc.) with a kaleidoscope of news, random facts, imposition of a variety of senses, blurring of stories and fixation on success lead to the abandonment of a quest for system and direction at the development of social processes and its replacement of the technologized approaches [3]. But is it worth following such thinking? After all, an individual loses thus the skills of rational thinking, needed to master the content of the university education. According to some researchers (L. Wecker and J. Crabtree of Stanford University, L. Yasukova, the Director of Social Psychology Lab at St. Petersburg State University, et al) the level of intelligence in humanity has decreased significantly in the recent decades [http://www.rosbalt.ru/main/2013/12/04/1207437.html]

[Date of access: 29.04.2017]. It is not an easy task for a modern student to even establish the links among the numerous courses taken at a modern university. Thus, knowledge doesn't develop itself into a coherent system that could be easily accessed if necessary.

There is a forming student's mindset type, refusing attempts at a clear structuring of information about the world, not exhibiting the systematic relations among the results of cognition of the different disciplines, not operating the basic concepts (good - evil, freedom - necessity, consistency, fact, etc.) and blurring the line between scientific and common knowledge. With this approach a clear argumentation about the expressed opinions and theses is often considered by the youth to be excessive, an appeal to reliable sources and long form texts seems to be boring and incomprehensible, and an utter "This is my opinion!" (even unsubstantiated and banal) is enough to replace a review with reliable facts and literature. The source of this superficiality of the learning process of the modern students lies, in my opinion, in a lack of mastering the fundamental principles and major methods of cognition.

So, how should the foundation for deep cognitive activities be built in the students, to facilitate further assimilation of the acquired knowledge in any given discipline?

The disadvantage can be filled only by the humanitarian and philosophical disciplines. However, there are not enough contact hours for such a serious methodological work, contrary to the values of the now emerging "society of knowledge" with its "knowledge is power" affirmation. But the power is a truly profound knowledge and not the imitation of such. 
Philosophy in the broad sense (including logic, ethics, etc.) should be the system-forming factor of the education, the core of the higher education, around which the rest of the courses would be built. No wonder, philosophy in the ancient world absorbed all the achievements of scientific thought of the time and it was easy for philosophy to navigate the concepts. Nowadays philosophy has consolidating property, binding numerous disciplines with various competencies by using common principles and epistemological norms. Fragmented specialized knowledge can become obsolete, disappear, useless, and what will be left? Inability to selfeducation... That was clearly visible in the West and in the USA in times of crisis, when the competence approach didn't prove itself flexible enough in the face of massive social mobility and the need for reskilling.

\section{What does philosophical education provide?}

Firstly, it provides depth to the education in any field, as philosophy introduces the youth to the highest achievements of the world, and not only to the results but also to the process of comprehension of the truth. As Hegel wrote, that is known for being known, is not yet cognized. Living examples of how the commonly known principles, norms, and concepts emerged, should introduce immature minds to an algorithm of rational successful approach on the example of great thinkers. Philosophy thus has an unsurpassed methodological significance to prepare the assimilation and manipulation of knowledge. However, the catastrophic reduction of the hours for studying this discipline unintentionally leads to the over-simplification of many philosophical concepts and, thus, their shallow absorption.

Secondly, the methodological importance of philosophical education is associated with formal logic, which is obviously underrated today in the list of the required disciplines. Logic was inherent to the preRevolutionary Russian gymnasiums and the schools of Stalin's time. The educational practice of the higher schools dictates nowadays the need to fill the lack of methodological knowledge and the introduction of open classrooms or courses "Methodology and Methods of Scientific Research". We should come out and say, that without mastering the basics of logical-philosophical knowledge, the aforementioned course couldn't be effective. Students need an in-depth practical course of logic (prior or during the course on methodology), allowing to understand the rational approaches and learn how to apply the much needed intellectual procedures, such as the selection of the essential features of a phenomenon, the ability to define, classify and organize phenomena, the ability to draw the right conclusions, to be precise in reasoning, etc.

These skills should translate into all spheres of knowledge.

Thirdly, philosophy provides an ethical meaning to the whole process of education. There are lots of talks lately about the importance of educating the youth at the higher schools. Formal activity in this area makes the process of education more external, introduced, at times obtrusive. The very content of philosophy, in the center of which stands an individual with his problems, has a deep moral sense that comes naturally to the students, via reflection and discussion of ethical and life-meaning issues that has a necessary pedagogical effect. Philosophy involves a student into a specific contextual field of culture, a world of values, and teaches how to navigate in them.

Many faculties nowadays have in their curricula courses like "Ethics of Business Relations", "Business Ethics", having a narrow practical focus; which is important and necessary in modern conditions. Yet without the theoretical training in the field of ethics, exploring the essence of the basic ethical categories, these courses look downsized, superficial, and not so effective.

Fourthly, the assimilation of philosophical knowledge contributes to the personal growth of a student and shaping of the outlook. Topics like "The Meaning of Life" used to cause great interest among the students, helping to solve the real life problems of young people [4]. Now, there are not enough contact hours for them.

However, there are no other courses in the higher schools, except for the Humanities, that would draw attention to selfidentity and self-fulfillment in accordance with E. Fromm's motto "To Be!". To be an active, open to reality, all-sided Individuality, interested in the world and its challenges, overcoming the limits of an isolated "Self". The prominent American philosopher Abraham Maslow studied the lives of famous accomplished and fulfilled people, identifying their characteristics. Among their inherent features was a vivid interest in the social problems and the world outside [5]. The researcher concluded that they were the Individuals with a capital "I", moved by the highest motives, overcoming the limits of their professional activity. "Self-actualizing people, bar none, are involved in a case beyond their own selfish interests, into something external to themselves" [6]. The modern society is still underway to realize the significance of the philosophical problems. Perhaps, the Russian society will be forced to pay a very high price for failure to understand timely the importance of philosophy. The shared problem of the modern specialists is their inability to speak the language of universal culture and universal values, to dialectically seize the sophisticated correlations and dominants in the rapidly changing world, to highlight the phenomena of fundamental importance, - led, unfortunately, to the globalization in purely economic sense. The making decisions, the emphasis is set on economic efficiency and profit and not on harmonization of relations in various systems, such as "Human - Nature", "Ethnos - Ethnos", "Human - Tech", "State - State" and so on [7].

Once proclaimed by the Russian government ideas of humanitarianization and humanization of education, quietly coming to nothing, reflected fairly the needs of a human society of the 21 st century in the specialists of a new type not only informed and professionally skilled, competent, making independent decisions, but also able to take social responsibility for their actions and behavior, foreseeing not only the immediate, but also the remote consequences for themselves and the world around. How not to recall the famous automobile magnate Henry Ford, who revealed the secrets of success on his "My Life and Work" [8]. He was 
confident that his business achievements are due to the spiritual guidance. The personality, according to Ford, must develop a certain philosophy of the relationship to reality, if he sees himself succeeding in the modern society. Ford's call to see the new horizons behind the specific economic activity, to keep in mind and consider in perspective the whole picture of the human community's development, its characteristics, and interests, is as relevant for the modern business and globalized economy as ever.

Since the times of Socrates, the philosophy course relies on a dialogical form, inherently interactive. Philosophy accepts such common nowadays formal methods as testing and so on only as a specific - and very limited - purpose. In this case knowledge doesn't develop within the listeners into a coherent structure to be easily updated and accesses if necessary. The practical exercises in philosophy should facilitate the acquisition of reasoning skills, expressing and defending the own standpoints, which are lacking in the current students in the dominant Internet communications era. Philosophy develops communication skills, helps the formation of personal qualities, self-development, and adequate self-esteem.

The higher education system should be responsible for the training of a highly-qualified specialist, as well as for the socialization of the personality, which lay today in the preparation for the living in an ever-changing diverse world, eco-information society. Education as an element of culture is not a mere obtaining of specific knowledge on nature, society or self, but the formation of the system of relations with nature, society and own place in the world based on knowledge.

\section{CONCLUSION}

The article describes just a few aspects of lecturing philosophy, allowing to increase the efficiency of educational and pedagogical processes at the universities. Yet only the listed aspects are enough to ensure that the gradual elimination of philosophical disciplines at the universities is not strategically justified and leads to intellectual educational catastrophe. Philosophical disciplines should become the backbone of the coherent system of other disciplines and their content. Meaningful philosophical education at the higher schools would certainly contribute to the deepening and systematization of the processes of cognition and education, allowing for training the specialists not only successful but also worthy.

To implement this we must move from the competencebased educational model to the value-based one. The prominent Russian scientist, Doctor of Engineering Science, Professor S.H. Karpenkov very accurately expressed the essence and necessity of such training in the higher schools: "It is invaluable creative process, cultivating accomplished, educated, and enlightened people, capable of doing great miracles in the name of saving the civilization and doing further good to all mankind" [9. P. 14].

\section{REFERENCES}

[1] Gumbrecht, Hans Ulrich, "Icy Embrace of "Science", or Why the Humanities Preferably Be "Humanities and Arts" // NLO, 2006, №81.

[2] Chistyakova, Olga V. "Relationship of Self and Other in Cultural and Religious Communications // Proceedings of the International Conference on Education, Language, Art and Inter-Cultural Communication. (ICELAIC 2016). Advances in Social Science, Education and Humanities Research, Volume 40. Xiamen, China. 2-4 December 2016. Paris: Atlantis Press, 2017. ISBN (on-line): 978-946252-292-3. P. 660-664.

[3] Chistyakova, Olga V. "Philosophical-anthropological meanings of postmodernism: "mediatizing" human" // Proceedings of the 2016 International Conference on Contemporary Education, Social Sciences and Humanities. 2016. C. 637-642.

[4] Ponizovkina, I.F., Agibalova E., "Loss of Life Purpose as a Problem of Modern Society" // Proceedings of the 2016 International Conference on Contemporary Education, Social Sciences and Humanities (ICCESSH 2016) The Conference Organizing Committee: Prof. Olga Chistyakova, Peoples' Friendship University of Russia (Russia); Prof. Yong Zhang, International Science and Culture Center for Academic Contacts, Russia; Dr. Natalia Jakovleva, St. Petersburg branch of the Financial University under the Government of the Russian Federation (Russia) and other. 2016. C. 657-662.

[5] Maslow, A., "Motivation and personality", Rev. ed. New York: Harper and Row. 1970.

[6] Maslow, A., "The father reaches of human nature", New Yolk: Viking. 1971.

[7] Ponizovkina, Irina, "Modern Intercultural Space and Problems of Eco-philosophy" // Proceedings of the 2016 3rd International Conference on Education, Language, Art and Inter-cultural Communication (ICELAIC 2016) Advances in Social Science, Education and Humanities Research. Xiamen. 2017. C. 639-642.

[8] Ford, H., "My Life and Work" http://www.improvement.ru/bibliot/ford

[9] Karpenkov, S.H., "The Freedom of Education, or Freedom From Education” // University Bulletin, 2011, №7 (127). 